Article

\title{
A positive Shift in the Public Acceptability of a Low-Carbon Energy Project After Implementation: The Case of a Hydrogen Fuel Station
}

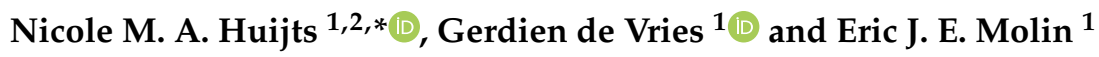 \\ 1 Faculty of Technology, Policy and Management, Delft University of Technology, \\ 2600 AA Delft, The Netherlands; G.deVries-2@tudelft.nl (G.d.V.); e.j.e.molin@tudelft.nl (E.J.E.M.) \\ 2 Department of Industrial Engineering \& Innovation Sciences, Eindhoven University of Technology, \\ 5600 MB Eindhoven, The Netherlands \\ * Correspondence: n.m.a.huijts@tue.nl
}

Received: 18 March 2019; Accepted: 9 April 2019; Published: 12 April 2019

\begin{abstract}
Public acceptability of low-carbon energy projects is often measured with one-off polls. This implies that opinion-shifts over time are not always taken into consideration by decision makers relying on these polls. Observations have given the impression that public acceptability of energy projects increases after implementation. However, this positive shift over time has not yet been systematically studied and is not yet understood very well. This paper aims to fill this gap. Based on two psychological mechanisms, loss aversion and cognitive dissonance reduction, we hypothesize that specifically people who live in proximity of a risky low-carbon technology-a hydrogen fuel station (HFS) in this case-evaluate this technology as more positive after its implementation than before. We conducted a survey among Dutch citizen living nearby a HFS and indeed found a positive shift in the overall evaluation of HFS after implementation. We also found that the benefits weighed stronger and the risks weaker after the implementation. This shift did not occur for citizens living further away from the HFS. The perceived risks and benefits did not significantly change after implementation, neither for citizens living in proximity, nor for citizens living further away. The societal implications of the findings are discussed.
\end{abstract}

Keywords: public acceptability; risk perception; loss aversion; cognitive dissonance reduction; hydrogen

\section{Introduction}

Low-carbon technologies are being stimulated by governments with the goal to reduce carbon emissions and the dreaded consequences of climate change. The successfulness of the introduction of these technologies depends, however, on many different factors, among which the evaluation of the technology by citizens, also called the public acceptability [1]. Even though citizens generally respond more favorably to sustainable technologies when they perceive more environmental benefits [1], citizens have been found to oppose sustainable technologies due to concerns about negative outcomes, such as safety risks [2,3]. As delays and cancelations are very costly in terms of public and private money, as well as in terms of reaching valuable carbon reductions, it is important to gain insight into the public acceptability of low-carbon technologies. Also from a democratic and ethical point of view, public acceptability should be weighed in the decision making on energy projects [4] and should therefore be known.

One challenge to relying on the public acceptability level of a technology is that it can change over time, and measurements taken at one time may not reflect measurements at a later time. This 
may cause policy decisions to be based on incorrect or incomplete information. As little insight is available about when and why fluctuations occur, it has been argued that more longitudinal studies are needed [5]. Public acceptability can either increase or decrease at a specific moment in time. Studies on nuclear energy acceptability have shown that accidents (i.e., in Chernobyl and in Fukushima) lead to more negative evaluations of nuclear power over time [6-9]. Other studies on low-carbon technologies have suggested that average evaluations can become more positive after the implementation of the technology. A review of case studies on public acceptability of wind farms in the UK and the Netherlands [10] has for example found higher support for wind farms after implementation compared to before. Also, studies on wave or tidal energy technologies $[11,12]$ have suggested that support increases after implementation, especially after some unexpected challenges have been tackled. While the negative change in nuclear energy evaluations due to accidents appears quite straightforward - through accidents people become more worried about the risks and therefore evaluate the technology overall as more negative-it is quite unclear why the average evaluation of a technology would become more positive once the technology is implemented.

In this paper, we study the effect of implementation on public acceptability. We discuss cognitive dissonance reduction and loss aversion as psychological mechanisms that can potentially explain why citizens would have a more positive overall evaluation of a low-carbon technology after its implementation than before. Cognitive dissonance reduction and loss aversion have been shown to take place in a variety of decision-making scenarios $[13,14]$, but have not yet been considered as relevant for explaining over-time changes in technology evaluations by citizens. Furthermore, we will explore the distance-dependence of these psychological mechanisms based on the premise that nearby living citizens will more likely perceive negative outcomes for themselves and are therefore more likely to exhibit the psychological mechanisms under consideration than citizens living further away. While several studies [15-17] have looked into the direct effects of actual or self-reported distance on public acceptability, to the best of our knowledge, no study has considered the moderating effects of distance on time-dependent evaluations of technologies.

\section{Theory and Hypotheses}

An obvious reason for why people may change their evaluation of a technology over time is an increase in practical experience and knowledge, due to interaction with the technology or to media attention or targeted information campaigns [11,18,19]. Because of increased experience and knowledge levels, people may perceive different types or levels of risks and benefits, and therefore evaluate the technology as a whole differently. They may perhaps learn over time that the benefits are larger than initially expected and the risks lower, or the other way around. However, an increase in experience and knowledge usually does not happen specifically at the moment of the implementation, especially when the technology is not frequently used by the public directly after implementation and when there is limited media attention on the days surrounding the implementation. An increase in experience and knowledge would therefore not explain a shift in the evaluation of a technology specifically around its implementation.

Two alternative reasons for evaluation change around the implementation moment are loss aversion and cognitive dissonance reduction. First, loss aversion is a cognitive bias that concerns the stronger weighing of losses and the weaker weighing of gains of a change in the status quo [20,21]. When people are asked to evaluate a technology that is about to be implemented, this means that they are evaluating a change in status quo, which can trigger loss aversion. In contrast, when people are asked to evaluate a technology that has already been implemented, they are actually asked to evaluate something that is already the status quo, and loss aversion is less likely occur.

Second, cognitive dissonance is also a bias that manifests itself as a psychologically uncomfortable state resulting from having two cognitions (knowledge, belief, or opinions) that are not consistent with each other $[14,22]$. When people are asked to evaluate a recently implemented technology in their living area, they may have several beliefs that are at odds with each other; they may for example feel 
strongly attached to their living environment, while at the same time perceive risks resulting from the new technology. These conflicting beliefs may cause cognitive dissonance, which is experienced as an unpleasant state or feeling. Particularly important conflicting beliefs [14], which both beliefs on safety and on the pleasantness of ones living environmental presumably are, can lead to strong dissonance. Research [14] has shown that this unpleasant state causes people to try to resolve the dissonance by either adding consonant or removing dissonant cognitions, or by changing the importance of consonant or dissonant cognitions. In the case of low-carbon technologies, cognitive dissonance might cause citizens to change their positive beliefs about their living environment in a neutral or negative way (and they might feel more willing to move away), or change their negative opinion about the technology into a more positive one so that they can be at ease again with their living environment. As this latter option has lower costs attached to it than the former one, the latter option may be more likely to occur. It may also be the case, that after implementation, people may lower their risk perception or decrease the importance of it, and/or increase the benefit perception or increase the importance of it.

Citizens will be most likely to exhibit cognitive dissonance reduction when they perceive serious negative outcomes for themselves because they then experience important dissonant beliefs that are in dire need of being resolved. Similarly, loss aversion will likely apply more strongly to personal losses than to other people's losses. It may be expected that people living nearer to a technology are more likely to perceive negative outcomes for themselves, such as safety risks, which very likely will be very important losses to them. Therefore, both loss aversion and cognitive dissonance reduction will more likely take place among citizens living in proximity of the technology than among citizens living further away.

Focusing on safety risks and environmental benefits as probably the most salient losses and gains respectively of the introduction of a low-carbon technology for citizens, and assuming that no accidents occur, we can formulate the following hypotheses:

- Higher perceived safety risks are associated with a more negative overall evaluation of the technology for both the in-proximity group (H1a) and the further-away group (H1b)

- Higher perceived environmental benefits are associated with a more positive overall evaluation of the technology for both the in-proximity group (H2a) and the further-away group (H2b) (we use the word 'overall evaluation' to indicate that we mean the evaluation of the hydrogen fuel station as a whole, to distinguish it from evaluations of the risks (called perceived risks) and the evaluation of the benefits (called perceived benefits). This overall evaluation is used to indicate public acceptability of the technology)

For citizens living in proximity of the implementation site, it is expected that there is a positive shift in the evaluation of the technology after implementation, meaning that these citizens will

- evaluate the perceived safety risks less negatively (H3a) and perceived environmental benefits more positively (H4a),

- $\quad$ evaluate the technology overall more positively (H5a), and

- weigh the perceived safety risks less strongly (H6a) and perceived environmental benefits more strongly (H7a) when judging the overall evaluation of the technology.

The effects presented under H3a until H7a are not expected to occur among citizens who live further away. For citizens who live further away of the implementation site, it is thus expected that there is no significant difference between before and after implementation in:

- the evaluation of the perceived safety risks and environmental benefits ( $\mathrm{H} 3 \mathrm{~b}$ and $\mathrm{H} 4 \mathrm{~b}$ respectively),

- the overall evaluation of the technology (H5b), and

- the effect of perceived risks and benefits on the overall evaluation of the technology (H6b and $\mathrm{H} 7 \mathrm{~b}$ respectively) 
Figure 1 depicts the hypotheses.

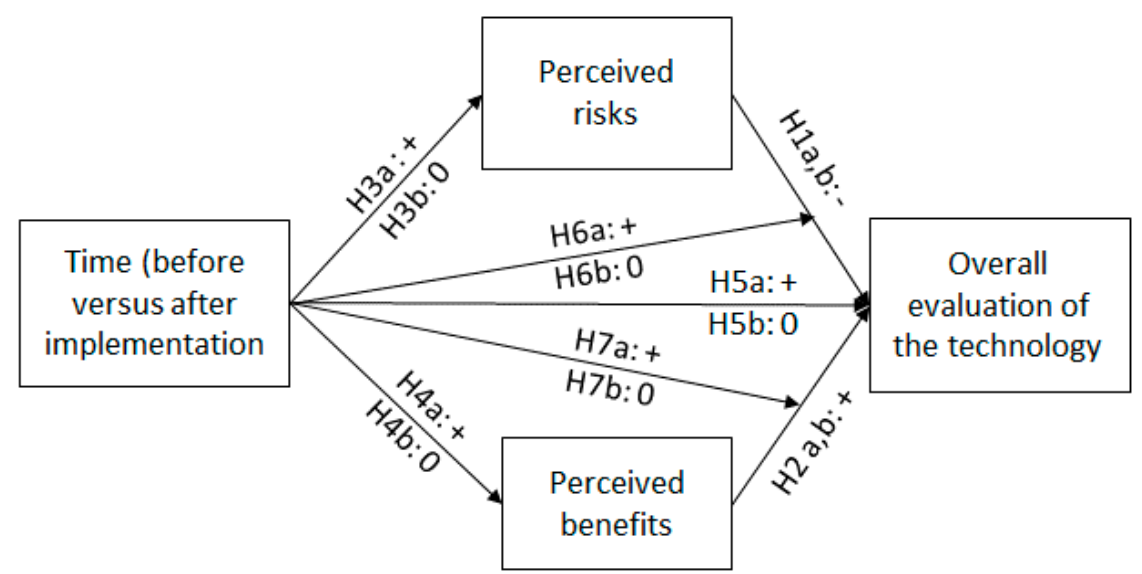

Figure 1. The hypotheses for the respondents living in proximity of the HFS (a) and for those living further away (b).

\section{The Case: A Hydrogen Fuel Station in the Netherlands}

The formulated hypotheses will be tested on the case of a hydrogen fuel station. Hydrogen can potentially replace fossil fuels as an environmentally-friendly and future-proof fuel for road transport [23]. Hydrogen can be produced from fossil fuels, but also from low-carbon sources such as electricity generated by wind or solar parks that is then used to split water into hydrogen and oxygen. Hydrogen vehicles that contain a fuel cell to convert hydrogen into electricity and an accompanying battery and electric engine do not emit gases other than water vapor and have no motor noise. Although battery-electric vehicles currently still have the upper hand in the market of low-carbon vehicles, the ongoing introduction of hydrogen technology in transport, such as in fuel stations, cars, buses, and trucks [24-29], suggests that hydrogen will get a considerable share in future transportation fuels. Furthermore, two important advantages that hydrogen-electric vehicles have over battery-electric vehicles are (1) that they have a higher energy storage capacity, and therefore a longer range, and (2) that they have faster charging time. If prices go down and hydrogen will be available in more places, these benefits could contribute to hydrogen vehicles attaining a considerable market share over time [23].

Like with other energy technologies, the risks of hydrogen fuel stations have been feared by citizens and have been a cause for objection. This was particularly the case for HFS projects that were situated close to where people live [3,17,30,31]. However, in one study performed in the UK [17], it was found that people living in the vicinity of a HFS expressed lower levels of opposition than people living somewhat further away. Cognitive dissonance reduction has been suggested as an explanation for this observation as nearby-living citizens might be "unwilling to acknowledge potential risks that they are exposed to" [17]. However, the study did not provide further evidence for this, and particularly also did not analyze differences between before and after implementation that could shed further light on this psychological mechanism and its time dependence.

The current paper focuses on the public acceptability of the first publicly accessible hydrogen fuel station of the Netherlands, which was placed in the city of Arnhem. For the production of hydrogen in this facility, biogas was purchased, and the technology could therefore be considered low-carbon. The HFS was annexed to an already existing fuel station, situated in an industrial area which borders a living area.

For several reasons, this case presents itself as a suitable case to test the presented hypotheses related to loss aversion and cognitive dissonance reduction. First, the HFS was rather close to people's homes, which may have been reason for concern about personal outcomes of the station that are likely to trigger the hypothesized psychological effects. Second, no accidents had taken place that could have 
simultaneously affected the citizens' evaluations of the HFS. Third, it was expected that citizens had not significantly gained relevant knowledge or practical experience around the time of implementation, which could have interfered with the hypothesized effects. Indeed, except for two small news items on television and a regional newspaper [32,33], there was no considerable media coverage or public outcry. Due to the fact that hydrogen vehicles were not yet on the market and only one or two vehicles were initially available to refuel at the filling station, it was also very unlikely that citizens living nearby would have gained practical experience with the technology or with its effects (e.g., personal fueling experience, outcomes such as cleaner air, increased traffic flows, etc.). Therefore, for this case it is likely that knowledge increase or gained personal experiences could not have caused possible differences in the evaluation of the hydrogen fuel station. Prior to testing the above hypotheses, we tested whether there was indeed no difference in knowledge level between before and after implementation, and additionally whether there was no difference in the awareness of hydrogen as a fuel and awareness of the local hydrogen fuel station (H0).

\section{Method}

\subsection{Data Collection Procedure}

A pen-and-paper survey was set out amongst residents living near the hydrogen fuel station that was officially opened on 3 December 2010, in the city of Arnhem, in the Netherlands. The streets north of the HFS, up to $1400 \mathrm{~m}$ of distance in a straight line, were targeted. The streets in which the questionnaires were distributed were quite close to the center of the town and had a mixed population of lower and higher income residents and a lot of students.

The focus of the study is specifically on the time shortly before and after the implementation, to capture the effect of implementation itself, rather than also the influence of wider societal events (i.e., specific accidents, strong media attention to related topics). Data were therefore collected within the 3 weeks preceding the official opening (the 'before implementation' group), and, as a result of the availability of research assistants, within the 5 months following the opening (the 'after implementation' group).

All households in the selected streets were approached. The households first received a letter that announced the research. The letter explained that citizens in Arnhem were specifically approached by the Delft University of Technology because a hydrogen fuel station would be or had been opened in their municipality on 3 December 2010 The name and address of the fuel station were mentioned to make sure that people were aware of the location of the HFS.

Each selected household was then visited by the principal researcher or one of the research assistants. Residents opening the door were asked whether one person in the household would be willing to complete a questionnaire related to the local hydrogen fuel station, preferably the one who's birthday came up first (to ensure randomization within the households). When nobody was at home, the address was visited again up to two more times to see if somebody would be at home. Of the residents that were at home and able to understand Dutch, approximately two-thirds participated. When someone volunteered to fill in the questionnaire, the interviewer made an appointment for picking it up after completion, or in some cases gave a return envelope. Each respondent participated only once in the study, so each participant either filled in the questionnaire after or before implementation.

The research assistants and principal researcher logged home addresses and date of completion on separate sheets, together with the number assigned to the handed-out paper questionnaire, so that the distance between the home and the HFS and time of filling in (before or after implementation) could later be determined.

At the moment of the development of the study, there were no ethical procedures in place yet. Therefore, we asked and received ethical approval for the study in hindsight from the Human Research Ethics Committee of the Delft University of Technology. 


\subsection{Sample}

In total, 329 respondents filled in the questionnaire. After removing cases with missing items on key variables (HFS evaluation, perceived risks, perceived benefits, distance, before/after implementation), 280 remained for further analyses. Of these, 172 filled in the questionnaire before implementation and 108 after implementation. The average age of the respondents was 41 years $(S D=13)$ and $52 \%$ were male. Sixty percent of the respondents had at least a bachelor's degree. Distances in a straight line between the individual respondents' addresses and the hydrogen fuel station were determined via Google Maps and ranged between $143 \mathrm{~m}$ and $1400 \mathrm{~m}(M=521, S D=317)$.

\subsection{Measures}

The questions in the questionnaire that are included in this study are formulated as follows.

Awareness and knowledge. We assessed awareness by asking "Did you know, before you received our letter or questionnaire, that hydrogen can be an alternative to petrol, diesel and LPG" and "Did you know, before you received our letter or questionnaire, that a hydrogen fuel station is going to be/has been placed in Arnhem?" (be or has been depending on whether the questionnaire was administered before or after implementation). We tested knowledge level with a nine-item test [15]. The test included five statements about the emissions of hydrogen vehicles and four about the chemical properties of hydrogen. The answer categories included true, false, and I don't know. For each correct answer, one point was scored. The resulting scale ranged from 0 to 9 points.

The overall evaluation of the hydrogen fuel station. We assessed respondents' evaluation of the hydrogen fuel station with four 5-point semantic differential scales following the question: "What do you think of the fact that a hydrogen fuel station is going to be/was added [depending on whether questionnaire was administered before or after implementation] to the AVIA fuel station at the Van Oldenbarneveldtstraat 9?": (a) I consider this a very bad idea (1)—a very good idea (5); (b) I find this a strong deterioration (1) —strong progression (5), (c) I find this useless (1)—very useful (5), (d) I find this not at all important (1) - very important (5). The average of the four items formed an index of evaluation, $\alpha=0.90$.

Perceived safety risks. Perceived risks of the station were measured with two items. The first question was "What are your expectations with respect to hydrogen fuel use instead of the current fossil fuels (benzene/diesel/LPG)?" The answer could range between 1 and 5: "I expect that hydrogen as a fuel is (1) very dangerous-(5) very safe.

The second question was "Can you indicate what your expectations are with respect to this specific fuel station?" Answer: "I expect that it will be (1) very dangerous-(5) very safe. The measurements were reverse-coded so that a higher score would mean more perceived risk. Then the items were averaged into one index, $\alpha=0.70$.

Perceived environmental benefits. The perceived environmental benefits were measured with four items. The first item asked "What are your expectations with respect to hydrogen fuel use instead of the current fossil fuels (benzene/diesel/LPG)?" Answer: "I expect that hydrogen as a fuel is (a) (1) much worse for the air quality-(5) much better for the air quality; (b) (1) much worse for the climate - (5) much better for the climate"; (c) (1) much worse for the environment-(5) much better for the environment. Then it was asked "Can you indicate what your expectations are with respect to this specific fuel station?". Answer: "I expect that it will have (1) a very negative-(5) a very positive effect on the environment'. The average of the four items formed an index of environmental benefit perception, $\alpha=0.83$.

A factor analysis over the individual items showed that each item loaded on the factor that it was theoretically assigned to.

The questionnaire was designed for multiple studies and contained many more items than the ones reported here. The full questionnaire in Dutch can be retrieved from the first author. The questionnaire was also developed alongside another questionnaire [15], and is having an overlap in items. 


\subsection{Distance Groups}

To be able to test the distance-dependent hypotheses, we split the sample into a 'in-proximity' group and a 'further-away' group. A study in the UK on HFS acceptability showed that within a 500-m range, a considerable percentage of respondents, namely $45 \%$, indicated to think that the placing of a local hydrogen fuel station would directly affect themselves [17]. Presumably a much lower percentage of people living further away would feel personally affected. We therefore took, admittedly rather arbitrarily, $500 \mathrm{~m}$ as a cutting point for dividing respondents into two distance groups. In the in-proximity group, 103 respondents filled in the questionnaire before the official opening of the HFS and 54 after the opening. In the further-away group, 69 filled in the questionnaire before opening and 54 after opening. See Table 1 for the number of participants in each quasi-experimental condition.

Table 1. The number of respondents per quasi-experimental group.

\begin{tabular}{cccc}
\hline & Before Implementation & After Implementation & Total \\
\hline Living in proximity $(<500 \mathrm{~m})$ & 103 & 54 & 157 \\
Living further away $(>500 \mathrm{~m})$ & 69 & 54 & 123 \\
\hline Total & 172 & 108 & 280 \\
\hline
\end{tabular}

To examine whether the four groups of this quasi-experimental design were similar in socio-demographic make-up, we compared the socio-demographic characteristics of the subgroups. A chi-square test showed that the differences in gender and education level did not significantly differ between groups. An ANOVA showed that age did significantly differ between groups. Pairwise comparisons between groups revealed that the in proximity - after group was significantly younger $(M=37 ; S D=9)$ than both the in proximity-before group $(M=42, S D=13 ; t(136.11)=2.98$, $p=0.003)$ and the further away - before group $(M=43, S D=11 ; t(102.49)=3.33, p=0.001)$, while no other differences were found to be statistically significant. To test whether the socio-demographic factors, and particularly age, should be controlled for in the further analyses, we tested whether the socio-demographic variables correlated with the most important psychological variables in the further analyses, being perceived risks, perceived benefits and the overall evaluation of the technology. The findings showed no significant correlations between the variables of interest, which suggests that differences in socio-demographic variables did not significantly affect the results. Therefore, we decided not to control for any of the socio-demographic factors in the further analyses.

\subsection{Analyses}

The analyses were conducted separately for the in-proximity group and further-away group using regression analyses. The hypotheses relating to the overall evaluation as a dependent variable were tested with hierarchical regression analyses. In step 1, the direct effect of time (before versus after implementation dummy) was added to the regression analysis. In step 2, the direct effects of perceived safety risks and perceived environmental benefits were added. In step 3, the interaction effects of time with perceived risks and with perceived benefits were added. Prior to the analyses, the variables were mean-centered to avoid problems with multi-collinearity [34]. We found that the assumption of normal distributions of residuals was not completely met for the regression in the first step, but was met for the regressions in the second and third steps. For directional hypotheses, an alpha of 0.10 was used and for non-directional hypotheses an alpha of 0.05 . Finally, the means of the psychological variables per quasi-experimental condition were inspected.

\section{Results}

A majority of the participants $(81 \%)$ indicated to be aware that hydrogen can be an alternative to petrol, diesel and LPG. Only a third (33\%; two missing items) indicated to be aware that a hydrogen fuel station was or had been constructed in Arnhem prior to being asked for participation in the study. 
The respondents had on average 4.19 of the nine items of the knowledge test correct $(S D=2.60 ; 17$ missing items). None of these findings were significantly different before and after implementation $(t(276)=0.75, p=0.452 ; t(278)=0.03, p=0.973$ and $t(261)=1.56, p=0.120$ respectively $)$ and thus were not affected by the implementation (confirming H0). The knowledge level of the participants in this study was a little bit lower than that of the participants of a national Dutch sample that completed a questionnaire with the same knowledge question around the same time [15]; those respondents scored 4.52 items out of the nine correct on average.

\subsection{Analyses for Respondents Living in Proximity}

First, we conducted all the analyses for the group living in-proximity of the HFS (see Table 2). We expected that those living in proximity of the HFS would evaluate the perceived safety risks less negatively and the perceived environmental benefits more positively after implementation (H3a and H4a). The regression analyses explaining perceived risks and benefits show that time (before versus after implementation) did not significantly affect the perceived risks and perceived benefits for people living in proximity. Hypotheses $3 \mathrm{a}$ and $4 \mathrm{a}$ respectively are therefore not supported.

Table 2. Regression analyses for respondents living in proximity.

\begin{tabular}{|c|c|c|c|c|c|c|c|c|c|c|}
\hline & \multicolumn{10}{|c|}{ Dependent Variables: } \\
\hline & \multicolumn{2}{|c|}{ Perceived Risks } & \multicolumn{2}{|c|}{ Perceived Benefits } & \multicolumn{6}{|c|}{ The Overall Evaluation of the HFS } \\
\hline & \multirow[b]{2}{*}{$\beta$} & \multirow[b]{2}{*}{$p$} & \multirow[b]{2}{*}{$\beta$} & \multirow[b]{2}{*}{$p$} & \multicolumn{2}{|c|}{ Step 1} & \multicolumn{2}{|c|}{ Step 2} & \multicolumn{2}{|c|}{ Step 3} \\
\hline & & & & & $\beta$ & $p$ & $\beta$ & $p$ & $\beta$ & $p$ \\
\hline Time & -0.11 & 0.184 & -0.06 & 0.448 & 0.15 & 0.054 & 0.13 & 0.045 & 0.14 & 0.027 \\
\hline Perceived risks & & & & & & & -0.38 & 0.000 & -0.32 & 0.000 \\
\hline Perceived benefits & & & & & & & 0.31 & 0.000 & 0.39 & 0.000 \\
\hline Time ${ }^{*}$ perceived risks & & & & & & & & & 0.16 & 0.034 \\
\hline Time $^{*}$ perceived benefits & & & & & & & & & 0.21 & 0.007 \\
\hline $\mathrm{R}^{2}$ & 0.01 & & 0.00 & & 0.02 & & 0.37 & & 0.40 & \\
\hline$\Delta \mathrm{R}^{2}$ & & & & & & & 0.34 & 0.000 & 0.04 & 0.014 \\
\hline
\end{tabular}

Note. Two-sided $p$ values are reported. Numbers in bold have $p$ values below $\alpha$ of $0.10 . n=157$. Time represents the before versus after implementation dummy.

We also expected that those living in proximity of the HFS would have a more positive evaluation of the technology after implementation as compared to before. The results of the hierarchical regression analysis in Table 2 shows that time indeed has a significantly positive effect on the overall evaluation, even when perceived risks and benefits and the interaction effects between time and perceived risks and benefits are controlled for. This means that hypothesis $5 \mathrm{a}$ is supported.

Furthermore, the hierarchical regression analysis explaining the overall evaluation shows that the perceived risks significantly negatively affect the overall evaluation, and the perceived benefits significantly positively affect the overall evaluation. This provides support for hypothesis 1a and 2a respectively. Finally, the analysis shows that the interactions of time with perceived risks and time with perceived benefits have a significant positive effect on the overall evaluation when controlled for the direct effects of the variables. A simple slope analysis shows that the effect of perceived risk on the overall evaluation is less negative after $(\beta=-0.13)$ than before implementation $(\beta=-0.41)$ while the effect of perceived benefit is more positive after implementation $(\beta=0.50)$ than before implementation ( $\beta=0.15$; see also Figure 2$)$. This confirms hypotheses 6 a and 7a respectively.

\subsection{Analyses for Respondents Living Further Away}

Table 3 presents the regression analyses for respondents living further-away from the HFS. We expected for citizens living further away that there would be no significant effect of time (before versus after implementation) on the perceived risks and benefits. The results in Table 3 show that time indeed did not significantly affect the perceived risks and perceived benefits for people living further away, which is in line with hypotheses $3 \mathrm{~b}$ and $4 \mathrm{~b}$. 

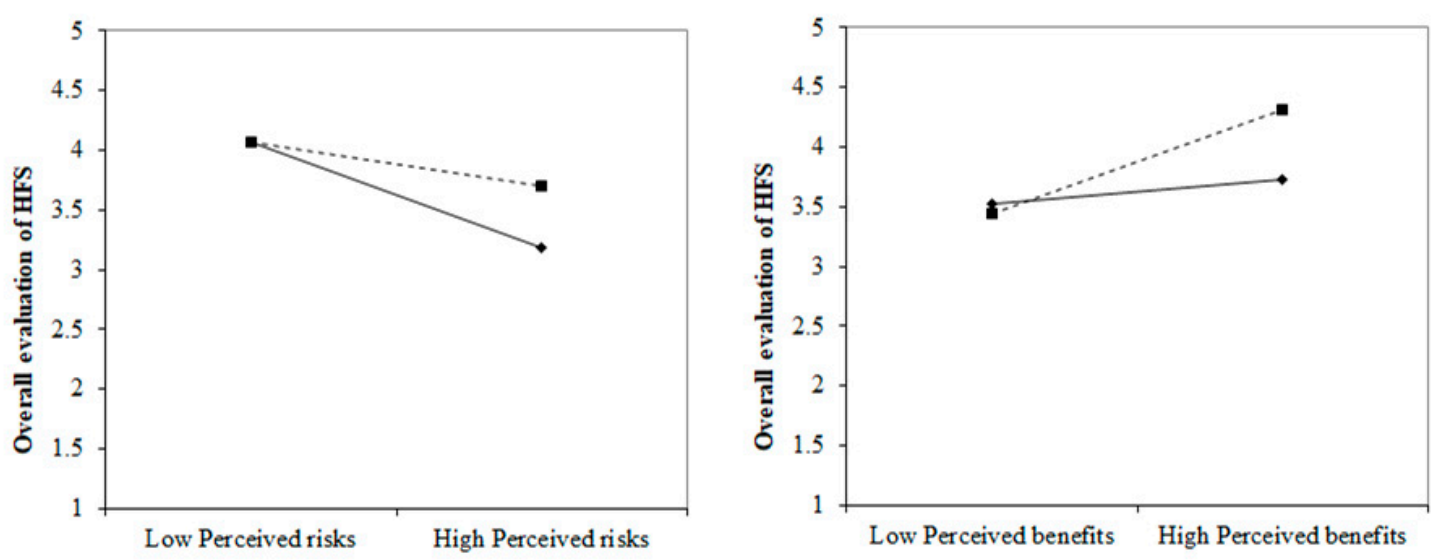

Figure 2. Single slopes of the effect of perceived risks (left) and perceived benefits (right) on the overall evaluation before (solid line) and after (dotted line) implementation.

Table 3. Regression analyses for respondents living further-away.

\begin{tabular}{|c|c|c|c|c|c|c|c|c|c|c|}
\hline & \multicolumn{10}{|c|}{ Dependent Variables: } \\
\hline & \multicolumn{2}{|c|}{ Perceived Risks } & \multicolumn{2}{|c|}{ Perceived Benefits } & \multicolumn{6}{|c|}{ The Overall Evaluation of the HFS } \\
\hline & \multirow[b]{2}{*}{$\beta$} & \multirow[b]{2}{*}{$p$} & \multirow[b]{2}{*}{$\beta$} & \multirow[b]{2}{*}{$p$} & \multicolumn{2}{|c|}{ Step 1} & \multicolumn{2}{|c|}{ Step 2} & \multicolumn{2}{|c|}{ Step 3} \\
\hline & & & & & $\beta$ & $p$ & $\beta$ & $p$ & $\beta$ & $p$ \\
\hline Time & 0.00 & 0.972 & 0.00 & 0.967 & -0.09 & 0.311 & -0.09 & 0.204 & -0.09 & 0.207 \\
\hline Perceived risks & & & & & & & -0.26 & 0.000 & -0.28 & 0.000 \\
\hline Perceived benefits & & & & & & & -0.28 & 0.001 & 0.48 & 0.000 \\
\hline Time* perceived risks & & & & & & & & & -0.08 & 0.361 \\
\hline Time* perceived benefits & & & & & & & & & -0.05 & 0.544 \\
\hline $\mathrm{R}^{2}$ & 0.00 & & 0.00 & & -0.09 & 0.311 & -0.09 & 0.204 & -0.09 & 0.207 \\
\hline$\Delta R^{2}$ & & & & & & & -0.26 & 0.000 & -0.28 & 0.000 \\
\hline
\end{tabular}

Note: Two-sided $p$ values are reported. Numbers in bold have $p$ values below $\alpha$ of $0.05 . n=123$. Time represents before versus after implementation.

The hierarchical regression analysis explaining the overall evaluation of the HFS (see Table 3 ) shows that the direct effect of time on the overall evaluation is not significant, neither when entered as a single predictor of the overall evaluation, nor when the perceived risks and benefits and the interaction effects between time and perceived risks and benefits are controlled for. This means that the overall evaluation of the HFS is not significantly different in the after than in the before-implementation subgroups and that hypothesis $5 \mathrm{~b}$ is supported by the data. The analysis further shows that the perceived risks significantly negatively affect the overall evaluation, and the perceived benefits significantly positively affect the overall evaluation. Hypotheses $1 b$ and $2 b$ are thus also supported in the further-away subsample. Finally, the analysis shows that the interaction effects of time with perceived risks and with perceived benefits are not significant. This provides support for hypotheses $6 \mathrm{~b}$ and $7 \mathrm{~b}$ respectively.

\subsection{Mean scores of the Psychological Variables}

Inspecting the mean scores of the psychological variables for the in-proximity group, we see that the mean overall evaluation was $3.64(S D=0.86)$ before implementation and $3.91(S D=0.76)$ after-implementation (see also Figure 3). Both scores were above the midpoint of the scale, indicating a somewhat positive evaluation of the local HFS. For the combined in-proximity sample, as there was no significant difference between before and after implementation, the mean perceived risk was $2.67(S D=0.75)$ and the mean perceived benefit $4.23(S D=0.62)$, suggesting that people perceived somewhat low risks and considerably high benefits. 


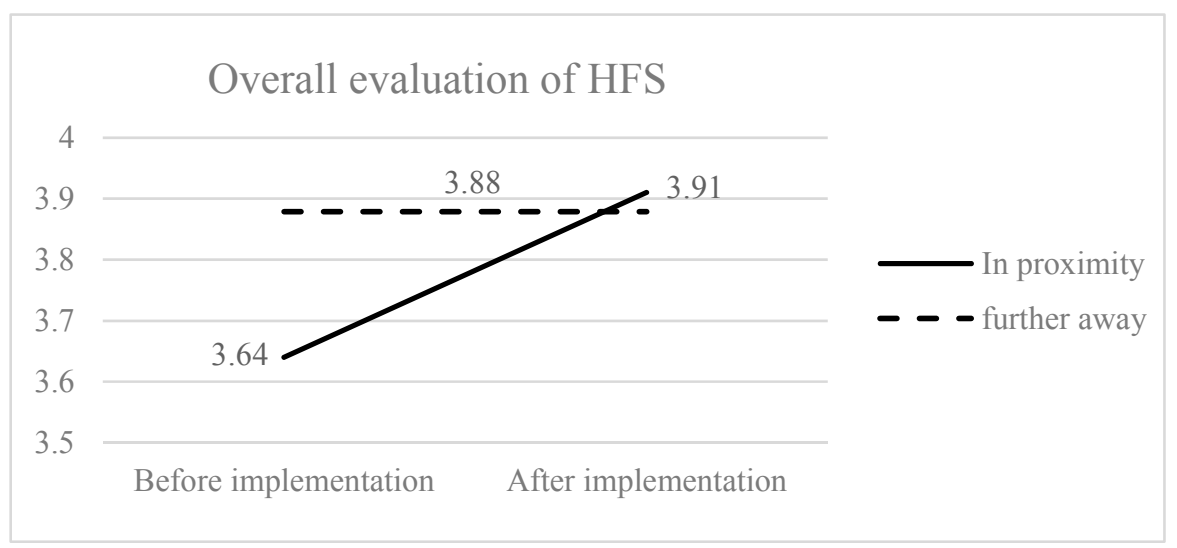

Figure 3. The overall evaluation of the local HFS, differentiated over time for the in-proximity group and not differentiated over time for the further away group.

For the total 'further-away' sample, without differentiation between before and after implementation as these were not significantly different, we find first that the mean overall evaluation is $3.88(S D=0.77)$. This indicates an acceptability level that is significantly higher than what the in-proximity respondents experienced before implementation $(t(224)=-2.20, p=0.029)$, but similar to the level that 'in-proximity' respondents experienced after implementation $(t(175)=0.25, p=0.802)$. This means that after implementation, the mean acceptability level of the in-proximity group rose to the level that the further-away group already had before implementation of the HFS (see also Figure 3). The mean score for perceived risks was $2.72(S D=0.76)$ and for perceived benefit $4.15(S D=0.67)$, which was quite similar to the means in the 'in-proximity' group $(t(278)=-0.59, p=0.554$ and $t(278)=$ $1.12, p=0.265$ respectively).

Appendix A shows the mean scores for each psychological measurement per distance and time group, and Appendix B shows the regressions of the overall evaluation on perceived risks and benefits for each distance and time group.

\section{Discussion}

In this paper, we argued that loss aversion and cognitive dissonance reduction are psychological mechanisms that can cause a more positive evaluation of a low-carbon technology after implementation, as compared to before implementation. In addition, we argued that they could lead to weaker weighing of perceived risks and stronger weighing of perceived benefits and to lower perceived risks and higher perceived benefits after the implementation. Finally, we argued that this would only happen among citizens living in proximity of the technology. These hypotheses were tested for the case of a hydrogen fuel station (HFS) with a between-subject design.

The findings largely supported the hypotheses. For those living in proximity of the HFS, the evaluation of the HFS was indeed more positive after implementation than before. In addition, in this distance group, the overall evaluation of the HFS was indeed also significantly less strongly influenced by perceived risks and significantly more strongly by perceived benefits after as compared to before implementation. As expected, these effects of implementation were not found for those living further away of the HFS location.

Different from what was expected, the perceived risks and benefits did not significantly differ between before and after implementation for those living in proximity of the HFS. Perhaps this finding is a result from the fact that we measured perceived risks and benefits in general and not for oneself. Possibly, loss aversion and cognitive dissonance reduction affect how people evaluate personal risks and benefits but not how they perceive the risks and benefits in general. There was also no effect of the implementation on perceived risks and benefits for the further away group, which was in line with our expectations. 
In the current study, comparisons were made between respondents, using a repeated cross-sectional design, and not within respondents. The benefit of interviewing different respondents after implementation than before implementation is that the measurements taken after implementation are not influenced by the measurements taken before implementation. To complement the findings in the current study, however, also longitudinal studies with repeated measures per respondent can be conducted. Furthermore, experimental studies could show whether the found effects can be replicated in a more controlled environment, while qualitative research could further uncover differences in how people think about a technology before and after it is implemented and whether there are also other losses and gains that are affecting the difference in the overall evaluation before and after implementation.

This study relied on the assumption that people living in proximity of a technology perceived more negative outcomes for themselves than people further away, and we used the relatively random demarcation of $500 \mathrm{~m}$ between 'in proximity' and 'further away'. Future studies could study how perceived personal outcomes diminish with distance to the implementation site, at which distance exactly a positive shift in the overall evaluation no longer occurs, and whether people that perceive more personal risks are indeed more prone to exhibit a positive shift in evaluations than people that perceive less personal risks. In addition, in the current study, people perceived limited risk and did not openly express opposition; many people were even not aware of the implementation of the local hydrogen fuel station at the moment we asked them to participate in the study. This begs the question whether the findings also hold for the implementation of low-carbon technologies for which strong risks are perceived and/or against which people have protested at some point of time and people are well aware of ahead of time (as is often the case for nuclear or wind energy).

Kermer et al. [35] showed that affective forecasting error explains why people in general tend to weigh negative outcomes of an upcoming change in status quo more strongly than after the change has occurred; they showed that prior to a change in status quo, people tend to overestimate the hedonic impact (negative feelings) that they will experience when enduring losses. When the change has occurred, however, people have psychological ways to cope with the negative outcomes, such as by applying cognitive dissonance reduction. Because of that, they have less strong negative feelings about the outcomes than anticipated beforehand. As citizens are not aware that such coping mechanisms will take place later on, they are not anticipating it and thus do not correctly predict how they will feel about a change after it occurs. Future studies in the energy technology context could similarly ask citizens living in proximity of a low-carbon technology project before implementation about the effect that they expect to feel afterwards and compare this with the effect that they actually report to feel afterwards. Differences in anticipated and actual affect could then perhaps explain the differences in evaluations and could provide further insight into the involved psychological processes.

Notwithstanding the limitations, the presented quasi-experimental field study provided a good case for studying a shift in the evaluation of a technology due to loss aversion and cognitive dissonance reduction as other factors that could simultaneously affect citizens' evaluation of the technology were absent (i.e., no increase in knowledge and personal experience), and a clear positive shift in the overall evaluation was discernible in the data for respondents living in proximity.

The current study also provides a good starting point for further research on the influence of loss aversion and cognitive dissonance on technology acceptability. For example, it would be interesting to assess the moderating effects of individual characteristics, type of technology, and situational and contextual factors (such as the possibility to move house or the level of control over the technology), on the extent to which loss aversion and cognitive dissonance reduction affect people's evaluation of a technology. Research could also be aimed at investigating how people can be inoculated [36] for the impact of cognitive biases on decision-making. This knowledge can be used for the design of 'debiasing' tools that empower the public to make well-informed and well-aware decisions. 


\section{Implications}

It is important for society to have a better understanding of fluctuations in local public acceptability of new low-carbon technologies and underlying mechanisms, as it can contribute to more successful combating of climate change.

For decision makers in government and industry, it is important to know that peoples' opinion about a technological project such as a HFS depends on when they are asked for their opinion (i.e., before or after implementation) and where they live (near of far). They should take such fluctuations into account in their policies. For example, when public acceptability would be important for permits it is good to realize that acceptability can increase after implementation among citizens living nearby.

Awareness of cognitive biases may also help citizens to make better decisions on whether to support or oppose low-carbon technologies such as hydrogen technology. In addition, the public debate might become fairer when opposition is fueled by conscious instead of unconscious cognitive processes [37]. Educational efforts can be targeted towards creating awareness of cognitive biases.

Our findings may sound very promising to those interested in introducing a low-carbon technology: Initial resistance among nearby living residents may weaken once the technology is in place. However, one should be careful not to discard the relevance of the initial resistance to a low-carbon technology. The uncertainty that people living in proximity experience when facing a new technology in their living environment should be responsibly responded to by policy makers and project owners. Information should be provided based on the information needs that citizens have, when and where they have them, rather than just based on what project-owners think citizens should know at specific locations and when they should know this [38]. This type of information provision requires dialogical interaction between developers and citizens over a longer period of time.

To conclude, policy makers, project developers, and citizens should be aware that public acceptability can change after implementation among citizens that live in-proximity of the technology. One-off polls that are not differentiated in time and location of citizens' homes vis-a-vis the technology do not provide sufficient information for longer-term responsible decision making and communication about low-carbon energy projects.

Author Contributions: Conceptualization, N.M.A.H., G.d.V. and E.J.E.M.; Formal analysis, N.M.A.H., G.d.V. and E.J.E.M.; Funding acquisition, E.J.E.M.; Investigation, N.M.A.H.; Methodology, N.M.A.H. and E.J.E.M.; Project administration, E.J.E.M.; Supervision, E.J.E.M.; Writing—original draft, N.M.A.H. and G.d.V.; Writing一review \& editing, N.M.A.H., G.d.V. and E.J.E.M.

Funding: The first author conducted this study largely while working for the Delft University of Technology, and has been supported financially by the Delft University of Technology and the Netherlands Organization for Scientific Research (NWO; grant numbers 276-20-012 and 313-99-312; the latter grant is co-funded by industry).

Acknowledgments: We are grateful to Bert van Wee for advising on the data collection, to three student assistants for collecting data, and to Baruch Fischhoff and Antal Haans for feedback to a draft version of the paper.

Conflicts of Interest: The authors declare no conflict of interest.

\section{Appendix A}

Table A1. Means and standard deviations per distance and time group.

\begin{tabular}{ccccc}
\hline & \multicolumn{2}{c}{ In-proximity Group } & \multicolumn{2}{c}{ Further-away Group } \\
\cline { 2 - 5 } & $\begin{array}{c}\text { Before } \\
\text { Implementation }\end{array}$ & $\begin{array}{c}\text { After } \\
\text { Implementation }\end{array}$ & $\begin{array}{c}\text { Before } \\
\text { Implementation }\end{array}$ & $\begin{array}{c}\text { After } \\
\text { Implementation }\end{array}$ \\
\hline & $n=103$ & $n=54$ & $n=69$ & $n=54$ \\
& $M(S D)$ & $M(S D)$ & $3(S D)$ & $M(S D)$ \\
\hline Evaluation of HFS & $3.64(0.86)$ & $3.91(0.76)$ & $3.94(0.78)$ & $3.80(0.75)$ \\
Perceived risks & $2.72(0.78)$ & $2.56(0.68)$ & $2.72(0.84)$ & $2.72(0.66)$ \\
Perceived benefits & $4.26(0.65)$ & $4.18(0.57)$ & $4.15(0.65)$ & $4.14(0.69)$ \\
\hline
\end{tabular}




\section{Appendix B}

Table A2. The overall evaluation of the HFS regressed on the perceived risks and perceived benefits per distance and time group.

\begin{tabular}{|c|c|c|c|c|}
\hline & \multicolumn{2}{|c|}{ Citizens Living in Proximity } & \multicolumn{2}{|c|}{ Citizens Living Further Away } \\
\hline & $\begin{array}{c}\text { Before } \\
\text { Implementation }\end{array}$ & $\begin{array}{c}\text { After } \\
\text { Implementation }\end{array}$ & $\begin{array}{c}\text { Before } \\
\text { Implementation }\end{array}$ & $\begin{array}{c}\text { After } \\
\text { Implementation }\end{array}$ \\
\hline & $\begin{array}{c}n=103 \\
\beta\end{array}$ & $\begin{array}{c}n=54 \\
\beta\end{array}$ & $\begin{array}{c}n=69 \\
\beta\end{array}$ & $\begin{array}{c}n=54 \\
\beta\end{array}$ \\
\hline Perceived risks & $-0.49 * *$ & -0.16 & $-0.22 *$ & $-0.32 * *$ \\
\hline Perceived benefits & 0.18 & $0.60^{* * *}$ & $0.51^{* * *}$ & $0.46^{* * *}$ \\
\hline $\mathrm{R}^{2}$ & 0.34 & 0.44 & 0.40 & 0.39 \\
\hline
\end{tabular}

Note: Two-sided $p$ values are reported. ${ }^{*} p<0.05,{ }^{* *} p<0.01,{ }^{* * *} p<0.001$.

\section{References}

1. Huijts, N.M.A.; Molin, E.J.E.; Steg, L. Psychological factors influencing sustainable energy technology acceptance: A review-based comprehensive framework. Renew. Sustain. Energy Rev. 2012, 16, 525-531. [CrossRef]

2. Brunsting, S.; De Best-Waldhober, M.; Feenstra, C.F.J.; Mikunda, T. Stakeholder participation practices and onshore CCS: Lessons from the Dutch CCS case Barendrecht. Energy Procedia 2011, 4, 6376-6383. [CrossRef]

3. Mumford, J.; Gray, D. Reconciling conflicting interpretations of risk. A case study about the siting of a hazardous plant. J. Commun. Manag. 2009, 13, 233-249. [CrossRef]

4. Taebi, B. Bridging the gap between social acceptance and ethical acceptability. Risk Anal. 2016, 37, $1817-1827$. [CrossRef] [PubMed]

5. Siegrist, M. The Necessity for Longitudinal Studies in Risk Perception Research. Risk Anal. 2013, 33, 50-51. [CrossRef]

6. Eiser, J.R.; Spears, R.; Webley, P. Nuclear attitudes before and after Chernobyl: Change and judgment. J. Appl. Soc. Psychol. 1989, 19, 689-700. [CrossRef]

7. Lindell, M.K.; Perry, R.W. Effects of the Chernobyl accident on public perceptions of nuclear plant accident risks. Risk Anal. 1990, 10, 393-399. [CrossRef] [PubMed]

8. Tsujikawa, N.; Tsuchida, S.; Shiotani, T. Changes in factors influencing public acceptance of nuclear power generation in Japan since the 2011 Fukushima Daiichi nuclear disaster. Risk Anal. 2016, 36, 98-113. [CrossRef]

9. Verplanken, B. Beliefs, attitudes, and intentions toward nuclear energy before and after Chernobyl in a longitudinal within-subjects design. Environ. Behav. 1989, 21, 371-392. [CrossRef]

10. Devine-Wright, P. Beyond NIMBYism: Towards an integrated framework for understanding public perceptions of wind energy. Wind Energy 2005, 8, 125-139. [CrossRef]

11. Bailey, I.; West, J.; Whitehead, I. Out of Sight but Not out of Mind? Public Perceptions of Wave Energy. J. Environ. Policy Plan. 2011, 13, 139-157. [CrossRef]

12. Dreyer, S.J.; Polis, H.J.; Jenkins, L.D. Changing Tides: Acceptability, support, and perceptions of tidal energy in the United States. Energy Res. Soc. Sci. 2017, 29, 72-83. [CrossRef]

13. Cummings, W.H.; Venkatesan, M. Cognitive Dissonance and Consumer Behavior: A Review of the Evidence. J. Mark. Res. 1976, 31, 303-308. [CrossRef]

14. Harmon-Jones, E.; Harmon-Jones, C. Cognitive Dissonance Theory. After 50 Years of Development. Z. Für Sozialpsychologie 2007, 38, 7-16. [CrossRef]

15. Huijts, N.M.A.; Van Wee, B. The evaluation of hydrogen fuel stations by citizens: The interrelated effects of socio-demographic, spatial and psychological variables. Int. J. Hydrogen Energy 2015, 40, 10367-10381. [CrossRef]

16. Chung, J.B.; Kim, H.K.; Rho, S.K. Analysis of Local Acceptance of a Radioactive Waste Disposal Facility. Risk Anal. 2008, 28, 1021-1032. [CrossRef] 
17. O'Garra, T.; Mourato, S.; Pearson, P. Investigating attitudes to hydrogen refuelling facilities and the social cost to local residents. Energy Policy 2008, 36, 2074-2085. [CrossRef]

18. Shaheen, S.A.; Martin, E.; Lipman, T.E. Dynamics in behavioral response to fuel-cell vehicle fleet and hydrogen fueling infrastructure. Transp. Res. Rec. 2008, 2058, 155-162. [CrossRef]

19. Molin, E. A causal analysis of hydrogen acceptance. Transp. Res. Rec.: J. Transp. Res. Board 2005, 1941, 115-121. [CrossRef]

20. Kahneman, D.; Tversky, A. Choices, values and frames. Am. Psychol. 1984, 39, 341-350. [CrossRef]

21. Tversky, A.; Kahneman, D. Loss aversion in riskless choice: A reference dependent model. Q. J. Econ. 1991, 106, 1039-1061. [CrossRef]

22. Festinger, L. A Theory Cognit. Dissonance; Row, Peterson: Evanston, IL, USA, 1957.

23. Ball, M.; Weeda, M. The hydrogen economy-Vision or reality? Int. J. Hydrogen Energy 2015, 40, 7903-7919. [CrossRef]

24. Fuel Cells Bulletin, Shell launches its first UK hydrogen station, with ITM and Linde. Fuel Cells Bull. 2017, 2017, 8 .

25. Fuel Cells Bulletin. Nel hydrogen stations for Shell and Toyota in California, and for Icelandic Hydrogen. Fuel Cells Bull. 2017, 2017, 8-9.

26. Fuel Cells Bulletin. Boreal Sjø, Wärtsilä partner to design ferry powered by hydrogen. Fuel Cells Bull. 2018, 2018, 6 .

27. Fuel Cells Bulletin. HTEC, Shell plan Canada's first retail hydrogen refueling station in Vancouver this year. Fuel Cells Bull. 2018, 2018, 1. [CrossRef]

28. Fuel Cells Bulletin. PitPoint station in Delfzijl to supply green hydrogen to two buses. Fuel Cells Bull. 2018, 2018,9

29. Fuel Cells Bulletin. Jülich, H2 Mobility analyse cost of battery, hydrogen infrastructure. Fuel Cells Bull. 2018, 2018,9

30. Hodson, M. Case 20: London CUTE Hydrogen Fuelling Station; The SURF Centre, University of Salford: Manchester, UK, 2006.

31. NBC News Gas Station First in the U.S. to Pump Hydrogen. Available online: http://www.nbcnews.com/ id/6460036/ns/us_news-environment/t/gas-station-first-us-pump-hydrogen/\#.VWx6kHttKG4. (accessed on 1 June 2015).

32. De Gelderlander. Eerste Tankstation Voor Waterstof Geopend in Arnhem; De Gelderlander: Arnhem, The Netherlands, 2010.

33. NOS Eerste Waterstof-Tankstation in Nederland Geopend. Available online: http://nos.nl/artikel/202686eerste-waterstof-tankstation-in-nederland-geopend.html (accessed on 2 December 2010).

34. Field, A. Discovering Statistics Using SPSS, 3th ed.; Sage Publication: London, UK, 2009.

35. Kermer, D.A.; Driver-Linn, E.; Wilson, T.D.; Gilbert, D. Loss aversion is an affective forecasting error. Psychol. Sci. 2006, 17, 649-653. [CrossRef]

36. Sagarin, B.J.; Cialdini, R.B.; Rice, W.E.; Serna, S.B. Dispelling the illusion of invulnerability: The motivations and mechanisms of resistance to persuasion. J. Personal. Soc. Psychol. 2002, 83, 526-541. [CrossRef]

37. De Vries, G. How positive framing may fuel opposition to low-carbon technologies: The boomerang model. J. Lang. Soc. Psychol. 2017, 36, 28-44. [CrossRef]

38. Alfano, M.R.; Huijts, N.M.A. Trust and distrust in institutions and governance. In Handbook of Trust and Philosophy; Simon, J., Ed.; Routledge: Abingdon-on-Thames, UK, Forthcoming.

(C) 2019 by the authors. Licensee MDPI, Basel, Switzerland. This article is an open access article distributed under the terms and conditions of the Creative Commons Attribution (CC BY) license (http://creativecommons.org/licenses/by/4.0/). 